\title{
Effects of Preoperative Enteral Nutrition Support on Postoperative Nutritional Status and Immune Function of Colorectal Cancer Patients
}

\author{
Dayong Ding $^{1, a,}$ Dan Wang ${ }^{2, b}$ Zhenbo Shu ${ }^{3, c}$ Correspondent Author
}

1,3 Department of Gastrointestinal Colorectal and Anal Surgery, China-Japan Union Hospital, Jilin University, Changchun, 130033

\author{
2 Operation Room of China-Japan Union Hospital, Jilin University, Changchun, 130033 \\ aemail, ${ }^{b}$ email, ${ }^{c}$ email,
}

Keywords: Enteral Nutrition, Colorectal Cancer, Preoperation, Immunity

\begin{abstract}
Background/aims: We performed a prospective randomized clinical trial to evaluate the effects of preoperative one week enteral nutrition (EN) support on the postoperative nutritional status, immune function and inflammatory response of colorectal cancer patients. Materials and Methods: 96 patients undergoing colorectal surgery were randomly divided into preoperative one week EN group (trial group, $n=48$ ) and preoperative normal food group (control group, $n=48$ ). The EN group was continuously treated with EN support for 7 days according to the treatment protocols before operation. The control group was given normal food. All the patients were checked for their body weight, upper arm circumference, white blood cell count (WBC), albumin (ALB), prealbumin (PA), C-reactive protein (CRP), humoral immunity (IgA, IgG), T cell subsets (CD4, CD8 and CD4/CD8), interleukin-6 (IL-6), tumor necrosis factor- $\alpha$ (TNF- $\alpha$ ) on the preoperative and the postoperative 1st and 7th day, respectively. Results: PA and IgG levels of the experimental group were higher than those of the control group on the postoperative 7th day, whereas IL-6 level of the experimental group was lower than that of the control group. Conclusion: Preoperative one week EN support for colorectal cancer patients will improve the postoperative nutritional status and immune function, alleviate inflammatory response of colorectal cancer patients.
\end{abstract}

\section{Introduction}

The prevalence of malnutrition is higher in colorectal cancer, when compared with other most common cancers(1). Malnutrition is more common in colorectal cancer than in non-GI cancers due to the direct effects of bowel obstruction and malabsorption. In the fields of nutrition and surgery, early enteral nutrition (EN) support has been demonstrated to play an important role in postoperative recovery. It has been verified that Appropriate and moderate nutritional intervention can improve the postoperative outcome of colorectal cancer patients (2). Lin et al. (3) reported that Preoperative total parenteral nutrition influences postoperative systemic cytokine responses after colorectal surgery. However, the effects of preoperative enteral nutrition support on postoperative nutritional status and immune function of colorectal cancer patients have seldom been discussed. In this study, we aimed to evaluate the nutritional status, immune function and inflammatory response indicators to investigate the effects of preoperative enteral nutrition support for colorectal cancer patients.

\section{Materials and Methods}

General Information. This was a prospective, randomized clinical trial conducted at Department of Gastrointestinal Colorectal and Anal Surgery, China-Japan Union Hospital. 96 patients with colorectal cancers requiring radical surgery from January 2013 to December 2014 were enrolled in this clinical study. The patients were randomly divided into 2 groups. the trial group (preoperative EN Group) and the control group (preoperative normal food group) equally. The study protocol was 
performed following the approval of the Institutional Review Board of China-Japan Union Hospital. All patients in both groups joined this study with informed consents. The exclusion criteria were age younger than 18 years, active preoperative infection, administration of corticosteroids or other immune-suppressive agents, gastrointestinal obstruction, respiratory or cardiac dysfunction, renal failure, hepatic dysfunction, and preoperative evidence of widespread metastatic disease.

Allocation Concealment. After enrollment, the random allocation sequences were orderly coded and sealed in opaque envelopes. After the eligibility of trial subjects were determined, patients in the same batch were matched according to their tumor staging, and were finally allocated to the corresponding groups after unfolding the envelopes orderly. Age, gender, BMI, tumor stage, ASA, surgical technique and tumor position of the patients in the two groups are summarized in table 1. No significant differences were observed.(table1).

Table 1.Patients characteristics of the 2 Groups

\begin{tabular}{l|c|c}
\hline \multicolumn{1}{c|}{$\begin{array}{c}\text { Patients } \\
\text { Characteristics }\end{array}$} & Trial(N=48) & Control(N=48) \\
\hline Age, year & $56(40-71)$ & $61(39-72)$ \\
Gender & $21(43.7 \%)$ & $23(47.9 \%)$ \\
$\quad$ Female & $27(56.3 \%)$ & $25(52.1 \%)$ \\
Male & $25.1 \pm 5.24$ & $24.7 \pm 4.13$ \\
BMI, kg/m2 & & \\
Surgical risk: ASA & $8(16.7 \%)$ & $10(20.8 \%)$ \\
$\quad$ ASA I & $30(62.5 \%)$ & $29(60.4 \%)$ \\
$\quad$ ASA II & $10(20.8 \%)$ & $9(18.8 \%)$ \\
$\quad$ ASA III & $8(16.6 \%)$ & $5(10.4 \%)$ \\
TNM & $32(66.8 \%)$ & $33(68.8 \%)$ \\
Stage I & $8(16.6 \%)$ & $10(20.8 \%)$ \\
Stage II & & $36(75.0 \%)$ \\
Stage III & $38(79.2 \%)$ & $12(25.0 \%)$ \\
Surgical technique & $10(20.8 \%)$ & $10(20.8 \%)$ \\
Laparoscopy & & $13(27.1 \%)$ \\
Conventional & $9(18.8 \%)$ & $25(52.1 \%)$ \\
Position & $15(31.2 \%)$ & 24(50.0\%) \\
Right hemicolon & Left hemicolon \\
Rectum & Quantitative variables are expressed as medians plus minimum and maximum values; \\
qualitative variables are expressed as absolute numbers and percentages. *p<0.05 \\
\hline
\end{tabular}

EN Support Protocol. Trial group: 1 week before operations, patients were administered orally with $1000 \mathrm{kcal} / \mathrm{d}$ intact protein EN powders on the base of semi-liquid diets (Leskon, Li Bang Clinical Nutrition Co, China)(model: 360g/tank, 230g/d). In addition, patients in trial group were also given glutamine powders 20g/d(Leskon, Li Bang Clinical Nutrition Co, China)(model: 90g/tank).

Control group: All the patients were received normal food.

Clinical Observation. Patients were examined daily during treatment, including the symptoms 
of nausea, vomiting, abdominal distention, abdominal pain, diarrhea and etc., the complications of intestinal obstruction, intestinal fistula and etc. Their recovery time of bowel movement was also recorded. Clinical status information including body weight, upper arm circumference of patients were measured on the day one-week before surgery, day 1 after surgery, and day 7 at the end of the study, respectively.

Laboratory determination: blood WBC, albumin, prealbumin and C-reactive protein (CRP) of the patients were determined on the 1st and 7th day before and after operations. Peripheral blood immunoglobulin (IgG), immunoglobulin $\mathrm{M}$ (IgM) and immunoglobulin A (IgA) were tested by the enzyme linked immunoassay. T cell subsets (CD4 + T cell, CD8 + T cell and CD4 + T cell/CD8 + T cell) were determined by the flow cytometry. Peripheral blood cytokine interleukin-6 (IL-6) and tumor necrosis factor- $\alpha$ (TNF- $\alpha$ ) were determined by ELISA(enzyme linked immunosorbent assay) (4).

Statistical Analysis. The statistics were expressed as mean \pm standard deviation $(\mathrm{x} \pm \mathrm{s})$ and analyzed by analysis of variance (ANOVA). Chi-squared test and test were used for comparison of the count data and measurement data respectively. Statistical analyses were conducted using SAS (statistical analysis system ) software program(version 9.0; SAS Institute Inc., NC, USA). P<0.05 was considered as statistically significant.

\section{Results}

Comparison between the Postoperative General Clinical Status of the Two Patient Groups. The two patients groups were treated according to the protocol. Bowel movement recovery time of the two groups was similar ( $>0.05$ ). The incidence of abdominal distention and abdominal pain in the trial group was similar to that in the control group $(\mathrm{p}>0.05)$. Besides, blood sugar, hepatic and renal functions and electrolytes of the two groups were also similar ( $>>0.05)$. (Table 2, 3).

Table 2. Comparison between the general clinical status of the two patient groups

\begin{tabular}{|c|c|c|c|c|c|c|c|}
\hline Group & $\begin{array}{c}\text { Case of } \\
\text { complication }\end{array}$ & $\begin{array}{c}\text { Bowel } \\
\text { movement } \\
\text { recovery } \\
\text { time (d) }\end{array}$ & $\begin{array}{c}\text { Venous } \\
\text { Blood sugar } \\
(\mathrm{mmoL} / \mathrm{L})\end{array}$ & $\begin{array}{c}\text { Glutamic } \\
\text { pyruvic } \\
\text { transaminase } \\
(\mathrm{u} / \mathrm{L})\end{array}$ & $\begin{array}{c}\text { Glutamic } \\
\text { oxaloacetic } \\
\text { transaminase } \\
(\mathrm{u} / \mathrm{L})\end{array}$ & $\begin{array}{c}\text { Serum } \\
\text { creatinine } \\
(\mu \mathrm{mmoL} / \mathrm{L})\end{array}$ & $\begin{array}{c}\text { Blood urea } \\
\text { nitrogen } \\
(\mu \mathrm{mmoL} / \mathrm{L})\end{array}$ \\
\hline Trial & 2 & $2.41 \pm 0.12$ & $5.81 \pm 1.01$ & $25.31 \pm 12.18$ & $27.35 \pm 7.43$ & $48.11 \pm 28.06$ & $1.56 \pm 2.66$ \\
\hline Control & 1 & $2.31 \pm 0.15$ & $6.01 \pm 1.03$ & $30.22 \pm 11.22$ & $26.21 \pm 7.02$ & $50.01 \pm 29.15$ & $1.48 \pm 2.41$ \\
\hline
\end{tabular}

Table 3. Comparison between the blood electrolytes of the two patient groups

\begin{tabular}{llllll}
\hline Group & $\begin{array}{l}\text { Blood sodium } \\
(\mathrm{mmoL} / \mathrm{L})\end{array}$ & $\begin{array}{l}\text { Blood potassium } \\
(\mathrm{mmoL} / \mathrm{L})\end{array}$ & $\begin{array}{l}\text { Blood calcium } \\
(\mathrm{mmoL} / \mathrm{L})\end{array}$ & $\begin{array}{l}\text { Blood phosphorus } \\
(\mathrm{mmoL} / \mathrm{L})\end{array}$ & $\begin{array}{l}\text { Blood } \\
(\mathrm{mmoL} / \mathrm{L})\end{array}$ \\
\hline Trial & $135.28 \pm 2.31$ & $4.18 \pm 0.47$ & $2.55 \pm 0.20$ & $1.28 \pm 0.28$ & $0.79 \pm 0.15$ \\
Control & $139.05 \pm 2.42$ & $4.32 \pm 0.65$ & $2.56 \pm 0.24$ & $1.24 \pm 0.27$ & $0.82 \pm 0.13$ \\
\hline
\end{tabular}

Comparison between the Nutritional Indicators of the Two Patient Groups. Body weight, upper arm circumference of the patients were similar before and after the study ( $>>0.05$ ). Albumin and prealbumin levels of the two patient groups decreased on postoperative 1 st day $(\mathrm{p}<0.05)$, and the two values rose at the end of the study $(\mathrm{p}<0.05)$. Prealbumin level of the trial group was higher than that of the control group on postoperative $7^{\text {th }}$ day $(236.2 \pm 38.5 \mathrm{mg} / \mathrm{L}$ versus $168.6 \pm 23.5 \mathrm{mg} / \mathrm{L}$, $\mathrm{p}<0.05$, Table 4). 
Table 4. Comparison between the nutritional indicators of the two patient groups

\begin{tabular}{llcccc}
\hline \multirow{2}{*}{ Group } & & $\begin{array}{c}\text { Body weight } \\
(\mathrm{kg})\end{array}$ & $\begin{array}{c}\text { Upper arm } \\
\text { circumference } \\
(\mathrm{mm})\end{array}$ & PA (mg/L) & ALB (g/L) \\
\hline \multirow{2}{*}{ Trial } & Preoperative & $54.4 \pm 21.2$ & $24.2 \pm 2.2$ & $237.2 \pm 27.5$ & $38.2 \pm 6.1$ \\
& Postoperative 1st day & - & - & $196.8 \pm 16.6$ & $35.8 \pm 7.4$ \\
& postoperative 7th day & $52.5 \pm 20.1$ & $24.0 \pm 2.0$ & $236.2 \pm 38.5^{*}$ & $33.5 \pm 3.3$ \\
\multirow{2}{*}{ Control } & Preoperative & $53.2 \pm 22.5$ & $24.3 \pm 1.8$ & $216.3 \pm 34.3$ & $38.5 \pm 2.8$ \\
& Postoperative 1st day & - & - & $185.5 \pm 45.2$ & $35.3 \pm 5.0$ \\
& postoperative 7th day & $51.7 \pm 21.2$ & $22.7 \pm 2.0$ & $168.6 \pm 23.5^{*}$ & $31.8 \pm 2.0$ \\
\hline
\end{tabular}

${ }^{*} \mathrm{p}<0.05$; PA: prealbumin; ALB: albumin

Comparison between the Immune Function Indicators of the Two Patient Groups. Immune function indicators of the two patient groups all decreased on postoperative $1^{\text {st }}$ day $(p<0.05)$ and conversely rose at the end of the study $(\mathrm{p}<0.05)$. IgG of the trial group was higher than that of the control group on postoperative $7^{\text {th }}$ day $(13.10 \pm 2.26 \mathrm{~g} / \mathrm{L}$ versus $10.43 \pm 1.91 \mathrm{~g} / \mathrm{L}, \mathrm{p}<0.05$, Table 5).

Table 5. Comparison between the immune function indicators of the two patient groups

\begin{tabular}{|c|c|c|c|c|c|c|}
\hline Group & & $\operatorname{IgG}(\mathrm{g} / \mathrm{L})$ & $\operatorname{IgA}(\mathrm{g} / \mathrm{L})$ & CD4+T cell (\%) & CD8+T cell (\%) & $(\mathrm{CD} 4+\mathrm{T}$ cell $) /(\mathrm{CD} 8+\mathrm{T}$ cell $)$ \\
\hline \multirow[t]{3}{*}{ Trial } & Preoperative & $11.42 \pm 1.68$ & $2.46 \pm 1.08$ & $37.25 \pm 5.46$ & $24.68 \pm 8.31$ & $1.62 \pm 0.61$ \\
\hline & $\begin{array}{l}\text { Postoperative 1st } \\
\text { day }\end{array}$ & $10.18 \pm 1.85^{*}$ & $2.31 \pm 1.13^{*}$ & $31.49 \pm 8.20 *$ & $22.61 \pm 8.69 *$ & $1.59 \pm 0.10^{*}$ \\
\hline & $\begin{array}{l}\text { Postoperative } 7 \text { th } \\
\text { day }\end{array}$ & $13.10 \pm 2.26 *$ & $3.25 \pm 1.52 *$ & $36.22 \pm 2.51 *$ & $25.16 \pm 9.65 *$ & $2.10 \pm 0.46^{*}$ \\
\hline \multirow[t]{3}{*}{ Control } & Preoperative & $12.82 \pm 3.49$ & $3.44 \pm 2.03$ & $35.31 \pm 9.42$ & $25.21 \pm 7.83$ & $1.44 \pm 0.55$ \\
\hline & $\begin{array}{l}\text { Preoperative } 1 \text { st } \\
\text { day }\end{array}$ & $9.63 \pm 2.44 *$ & $2.46 \pm 1.58 *$ & $28.69 \pm 4.55^{*}$ & $24.33 \pm 9.26 *$ & $1.42 \pm 0.51^{*}$ \\
\hline & $\begin{array}{l}\text { Postoperative } 7 \text { th } \\
\text { day }\end{array}$ & $10.43 \pm 1.91 *$ & $4.13 \pm 3.06 *$ & $33.26 \pm 4.25 *$ & $24.48 \pm 7.79 *$ & $1.73 \pm 0.49 *$ \\
\hline
\end{tabular}

${ }^{*} p<0.05, * * p<0.01 ;$ Ig: Immunoglobulin; CD: cluster of differentiation

Comparison between the Inflammatory Response Indicators of the Two Patient Groups. Inflammatory response indicators and cytokines of the two patient groups all increased on postoperative 1 st day $(\mathrm{p}<0.05)$ and reduced at the end of the study $(\mathrm{p}<0.05)$. IL-6 of the trial group was lower than that of the control group on postoperative $7^{\text {th }}$ day $(486.23 \pm 81.45 \mathrm{ng} / \mathrm{L}$ versus 406.48 $\pm 90.81 \mathrm{ng} / \mathrm{L}, \mathrm{p}<0.05$, Table 6). 
Table 6. Comparison between the inflammatory response indicators of the two patient groups

\begin{tabular}{llcccc}
\hline \multirow{2}{*}{ Group } & & IL-6 $(\mathrm{ng} / \mathrm{L})$ & TNF- $\alpha(\mathrm{ng} / \mathrm{L})$ & $\begin{array}{c}\text { WBC } \\
\left(10^{9} / \mathrm{L}\right)\end{array}$ & $\begin{array}{c}\text { CRP } \\
(\mathrm{mg} / \mathrm{L})\end{array}$ \\
\hline \multirow{2}{*}{ Trial } & Preoperative & $333.56 \pm 72.58$ & $91.38 \pm 27.51$ & $4.82 \pm 1.10$ & $1.48 \pm 0.51$ \\
& Postoperative 1st day & $534.71 \pm 126.56^{*}$ & $133.25 \pm 32.59^{*}$ & $11.23 \pm 4.53^{*}$ & $1.42 \pm 0.59^{*}$ \\
& Postoperative 10th day & $486.23 \pm 81.45^{*}$ & $116.88 \pm 80.95^{*}$ & $7.29 \pm 2.25^{*}$ & $1.67 \pm 0.46^{*}$ \\
\multirow{2}{*}{ Control } & Preoperative & $311.11 \pm 76.65$ & $91.56 \pm 19.81$ & $5.35 \pm 1.28$ & $1.62 \pm 0.52$ \\
& Preoperative 1st day & $311.08 \pm 151.59^{*}$ & $124.66 \pm 29.24^{*}$ & $12.10 \pm 4.16^{*}$ & $1.61 \pm 0.92^{*}$ \\
& Preoperative 10th day & $406.48 \pm 90.81^{*}$ & $115.63 \pm 22.39^{*}$ & $6.81 \pm 2.61^{*}$ & $2.09 \pm 0.41^{*}$ \\
\hline
\end{tabular}

\section{Discussion}

Colorectal cancer patients commonly suffer from malnutrition owing to the nature of colorectal cancer and adverse effects such as operative trauma and perioperative diet control and low-calorie intake(1). Tumor progression is often accompanied by malnutrition and poor immune function. Radical surgeries of colorectal cancer will up-regulate the catabolism of patients and lead to immune depression (5). Besides, surgical stress will result in systemic inflammatory response, decrease the quality of life and even affect prognosis(6). Therefore, rational and effective nutrition support will be conductive to malnutrition cancer patients. The function of intestines is usually normal before operation, which allows the wide application of preoperative EN support in clinical practice.

EN support products are mainly classified into three types: amino acid or short peptide (element type), intact protein (non-element type) and component. Short-peptide type (element type) products can be absorbed after several steps of digestion utilizing protein hydrolysates as the nitrogen sources, which are applicable to the patients right after surgeries $(7,8)$. Thus, we provided various EN agents for the patients at preoperative stage according to their gastrointestinal functions. In order to reduce the preoperative malnutrition of colorectal cancer patients, they were administered with $230 \mathrm{~g} / \mathrm{d}$ intact protein EN powders and glutamine powders 20g/d orally. The comparisons between albumin, prealbumin, immune function, IgG, cytokine and IL-6 in both groups suggest that partial preoperative EN support will not only improve the postoperative nutritional status and immune function, but also moderate the inflammatory response of colorectal cancer patients after operative trauma.

Moreover, partial preoperative EN support has been verified to facilitate the postoperative gastrointestinal absorption of nutrients, accelerate the recovery of patients, and enhance the overall clinical outcome. It is also noted that previous study reported that nutrition support should be limited to colorectal cancer patients who severely malnourished (9), the present study did not address in this regard. Further efforts are still in need to ensure the safe utilization of preoperative enteral nutrition to colorectal cancer patients.

In conclusion, preoperative enteral nutrition support can improve the nutritional status as well as immune function, alleviate inflammatory response, and facilitate the recovery of colorectal cancer patients undergoing radical surgery.

\section{References}

[1] Hu WH, Cajas-Monson LC, Eisenstein S, Parry L, Cosman B, Ramamoorthy S. Preoperative malnutrition assessments as predictors of postoperative mortality and morbidity in colorectal 
cancer: an analysis of ACS-NSQIP. Nutr J. 2015;14:91

[2] Chen Y, Liu BL, Shang B, et al. Nutrition support in surgical patients with colorectal cancer. World J Gastroenterol. 2011;17(13):1779-86.

[3] MT. Lin, H. Saito, R. Fukushima et al. Preoperative total parenteral nutrition influences postoperative systemic cytokine responses after colorectal surgery. Nutrition. 1997;13(1):8-12

[4] Vasilatos SN, Broadwater G, Barry WT, et al. CpG island tumor suppressor promoter methylation in non-BRCA-associated early mammary carcinogenesis. Cancer Epidemiol Biomarkers Prev 2009; 18: 901-14.

[5] Liu Y, Tao KX, Wang GB, et al. Effect of enteral nutrition as replacement of traditional bowel preparation on the intraperitoneal and intraluminal disseminated tumor cells, recurrence and metastasis in patients with colorectal cancer. Zhonghua Wei Chang Wai Ke Za Zhi. 2013; 16(4):350-3.

[6] Garth AK, Newsome CM, Simmance N, Crowe TC. Nutritional status, nutrition practices and post-operative complications in patients with gastrointestinal cancer. J Hum Nutr Diet 2010; 23:393-401.

[7] Bozzetti F, Braga M, Gianotti L, Gavazzi C, Mariani L. Postoperative enteral versus parenteral nutrition in malnourished patients with gastrointestinal cancer: a randomised multicentre trial. Lancet 2001; 358: 1487-92.

[8] Georgiannos SN, Renaut AJ, Goode AW. Short-term restorative nutrition in malnourished patients: pro's and con's of intravenous and enteral alimentation using compositionally matched nutrients. Int Surg 1997; 82: 301-6.

[9] Liu MY, Tang HC, Hu SH, et al. Influence of preoperative peripheral parenteral nutrition with micronutrients after colorectal cancer patients. Biomed Res Int. 2015; 2015:535431. 